\title{
Dialogic Inquiry of Family Conversations in Museum Exhibits Designed for Family Engagement
}

\author{
Christen Foehring, Anna Keefe, Ashley Kliefoth, Katherine Murphy \\ Harvard Graduate School of Education
}

\begin{abstract}
This study builds on previous museum research investigating family engagement, interaction and exchange of knowledge in museum exhibits. Family dialogue was gathered and analyzed at the New England Aquarium (NEA), USS Constitution Museum (USS), and the Boston Children's Museum $(B C M)$. Specifically, we asked the question: "What types of learning are demonstrated through family discourse in museum and aquarium exhibits?" After identifying dialogical patterns through pilot research, our team created six coding categories to track types of learning. These coding categories were: command/exclamation; making connections; reinforcement/coaching; naming; explanation; and housekeeping. Results were analyzed to provide insight into general family learning patterns in museums and exhibit-specific responses. For instance, in addition to different types of collective knowledge construction by families in museums, parents were found to be teaching social and lifeskills, and demonstrating effective learning strategies for their children. A discussion of dialogue observed in each museum exhibit further explores which elements of the exhibit design may have been encouraging unique learning and interaction, and what opportunities this presents for further research.
\end{abstract}

\section{Introduction}

When exploring museum exhibits families often engage in dialogue that allows members to share information and enhance the collective learning experience. In this study, we analyzed family dialogue at the New England Aquarium (NEA), USS Constitution Museum (USS), and the Boston Children's Museum (BCM). Specifically, we asked the question: "what types of learning are demonstrated through family discourse in museum and aquarium exhibits?"

\section{Literature Review}

Since the late 1980s there has been a growing interest in investigating family learning in nontraditional settings, such as museums, aquariums, and zoos [1] [5]. Families enter museums with their own agendas, prior knowledge, and expectations. As families navigate museum exhibits, they engage in dialogue that allows family members to make meaning of exhibits while drawing from existing values and reinforcing shared experiences [5]. These characteristics differentiate family learning experiences in museums from those experiences of individuals, school groups, or groups of adults and call for special consideration on the part of museums.

The focus of much of the early research on family learning in museums was descriptive in nature and centered on the ways in which families behaved in museums. In some studies, researchers concentrated on determining the roles of family members in creating shared learning experiences. For example, parents often took on a didactic teaching role, providing explanations of content, interpreting children's comments, and labeling or naming objects [1]. Other studies documented families' interactions with exhibits by tracking visitors in the museum and recording the amount of time they spent at various exhibits [5][7]. During these studies, it was assumed that the more time a family spent at an exhibit, the more they learned from it [5].

More recently, researchers have been concentrating on family dialogue at specific exhibits within the larger museum context [5]. Using dialogue to analyze learning has long been practiced in classrooms and other traditional settings. However, it is relatively new to the museum research field [1]. Family dialogue reveals a lot about the types of learning taking place, as family members often explain phenomena, ask and answer questions, and relate exhibit information to shared experiences [5]. Investigating dialogue in museum exhibits also allows a closer look at how learners build understanding by working with family members to scaffold their knowledge [1]. Children on a family museum trip have a unique opportunity to access adult knowledge, and different areas of expertise held by siblings, bringing these together to inform and enhance their experience.

Borun et al. [4] conducted a series of studies in which they examined families' responses to exhibits, both as a function of time spent in an exhibit and in terms of the quality of family discourse within the exhibit. Results of these studies indicate that time spent in exhibits and the quality of conversations about the exhibits influence family learning. They concluded that the best-designed exhibits for learning are those that slow the pace of visitors by increasing involvement with the exhibit and interaction with others in order to foster dialogue and create a rich learning environment [4]. 
As museums recognize that families comprise a large percentage of their visitors, the need to create exhibits that appeal to families' agendas has become a priority [3][5]. In order to satisfy such demands, museums need to know what types of experiences families seek in museums and what sorts of exhibits provide these experiences. Perhaps not surprisingly, research has shown that families seek entertainment and learning experiences in museums [5]. Little research has been done, however, on what that learning looks like. Family conversations have proven effective in examining learning in museum settings [1] [4] [5]. Thus, family discourse was selected for this study to investigate the diversity of learning taking place in museum and aquarium exhibits.

\section{Research Methods}

\subsection{Pilot Research}

We conducted the majority of our formal pilot research at the New England Aquarium due to the tentative status of permission from the Boston Children's Museum and the USS Constitution Museum. ${ }^{1}$ Informal observations, however, took place at all three sites. We paid attention to exhibit layout and documented family conversations through note taking and narrative writing without coding. Early pilot research at the all three sites consisted of speaking with exhibit and education coordinators about the rules and regulations regarding outside research within the museums and aquarium.

In the next stage of pilot research, exhibits were examined to determine potential for use in data collection. Factors considered were acoustics, potential for family engagement, consistent flow of visitors through the exhibit space, and researcher positioning within the exhibit. Consideration of these factors led us to choose the "Kid Power" exhibit at the Boston Children's Museum and the "All Hands on Deck" at the USS Constitution Museum. Researchers at the New England Aquarium had initial challenges with acoustics in some exhibits, and changed locations to the "Amazing Jellies" exhibit. Specifically, they focused on a walk around tank entitled "Japanese Sea Nettles" and a colored lighting tank entitled "Moon Jellies." The exhibit design allowed visitors to move around so that the researchers could better see their faces and movements in relation to one another.

We also piloted our proposed approach to documenting and coding family conversations. Initially, we had discussed having both observers simply document the entire conversation and then code the conversations afterwards. We experimented

\footnotetext{
${ }^{1}$ Since completion of the pilot research, we have confirmed all permission issues with all three museums.
}

with this practice but found that it caused us to lose vital information, as it was difficult to record the details of the conversation while observing the visual cues and context. We preferred to have the coding researcher keep her visual attention focused on the family group and note their actions and demeanors as she numbered and categorized each statement. After a family group had left the exhibit space, the note taker and the coder could compare and combine their observations to create a full, well-rounded depiction of the conversation. If there were too many contradictions, the data set would be thrown out.

After initial pilot research, the layout of the coding sheet was altered to include category definitions on an attached page for easy reference and spaces for recording the age range and time spent in the exhibit. We established six coding categories, some of which were further clarified and divided into sub-topics. Each of these categories was recorded as a question, answer, or comment. They were as follows:

1. Command/Exclamation: An abrupt excited utterance or a direction or instruction to do something (examples: "Wow!" "Look!" "Come here," "Interesting," "Be quiet," etc.)

2. Making Connections - Role Playing: An individual plays at or pretends to occupy the role of another (examples: "Man overboard!" "I almost fell in the water, "We're 100 feet high!" "I'm a jellyfish!" "This is where you would sleep if you were a sailor") Making Connections - Relate to Personal Experience: Individual uses the word(s) I, we, me, my, our(s), us, or a proper name to connect to the exhibit (examples: "It looks like the jellyfish we saw at the beach," "My brother is as tall as that sailor." Making Connections - Relate to Prior Knowledge: Individual references prior knowledge to connect to the exhibit. (Examples: "That jellyfish has a mane like Simba," "That looks like a pirate ship from the movie." 3. Reinforcement/Coaching: Statement of support, praise, encouragement, confirmation, or criticism (examples: "Good job!" "Pull harder!" "Try it this way," "Take turns") 4. Naming: The verbal act of assigning a name to an aspect of the exhibit (examples: "It's a "," "Look at the ,"What is this?") 5. Explanation: A statement or question that makes something comprehensible by describing the relevant structure or operation or circumstances (examples: "Why does it have long tentacles?" "The tentacles are long because they are used for grabbing stuff to eat, "Scurvy is a disease caused by not eating enough vegetables.") 6. Housekeeping: Statements or questions in reference to routine tasks and procedures (examples: "I'm hungry," "Where is the bathroom?" "It is time to go.")

The pilot research helped to create and clarify these categories so that they were broad enough to chart similar learning tendencies across museums. 
This included in depth discussions of how each of the categories should be interpreted according to the unique dialogical patterns emerging in each exhibit. For instance, at the USS Constitution Museum, it was decided that role-playing encompassed not only explicit dramatic enactments, but also verbal demonstrations that visitors were imagining life in another time and place. For instance, the comment "I need help over here! Whoa!“" was coded as roleplaying because the girl was pretending to be a sailor unfurling the sail. Role-playing at the New England Aquarium was defined as children pretending to be jellyfish or engaging in jellyfish-like behaviors, such as swimming. Prior knowledge and personal experience proved to be less separable than they were initially stated in the coding sheet, as it was difficult to determine the origins of knowledge from a single comment. Thus, for the purposes of data analyses, prior knowledge and personal experience were examined holistically, rather than separately. In addition, some conversations spanned more than one category, making it necessary to double code them. For instance, at the USS Constituion "Yes! Like that and like that! Go!" was coded as both Reinforcement and Explanation.

\section{Inter-Rater Reliability}

As the four researchers worked in pairs, it was decided that it was necessary to re-code a sample of each pair's results in order to determine the degree of inter-rater reliability between the research teams. In order to do this, each member of the research team re-coded a sample from each museum she did not visit. When each individual re-coded the conversations, she conferred with her research partner to see how, if at all, their individual coding overlapped. For each research pair, the rate of reliability was high, despite a handful (1-2 maximum for each conversation) of instances in which there was discrepancy. When discrepancies occurred between members of the same pair, they often agreed that either option would be acceptable, but differed in which option they thought was "best." After each pair discussed their individual results, the two groups reviewed their overall re-coding sheets. Thus, the researchers who visited the New England Aquarium reviewed their re-coding sheets for the Boston Children's Museum with the researchers from that museum, and vice versa. Inter-rater reliability between pairs who had been to the museum for which they were coding, was not as high as that between members of the same pair.

As a result of the discussion of the re-coding of the data, it was clear that the context in which the conversations took place was critical. Voice intonation was also a key component in explaining the differences in coding, particularly with regard to asking questions, reinforcement, and command/explanation. For the Boston Children's Museum, more so than the New England Aquarium, comments such as, "I'm using my weight," were coded as explanation because the context was such that the child was explaining what he was doing, not simply exclaiming. Further, comments such as "Whoa," were difficult to code without context, even if the initial coders also provided some notes as to what actions accompanied the statement. Researchers who were not present at the Boston Children's Museum when these types of comments were made were likely to code them as command/exclamation comments, assuming that they were simply statements of excitement and awe. Researchers, who were present, coded them as reinforcement, seeing that these comments were meant to praise and encourage a child's actions within the exhibit. Despite these differences, interrater reliability was very high, and discrepancies were a result of missing contextual information, not a result of any misunderstandings about previously agreed meanings of the categories.

\section{Results}

Our dataset was large enough that generalizations were helpful, but differences between and within the museums also proved interesting. At all three sites, adults spoke more than children they accompanied and verbal observations were the most common comment among children and adults. However, the frequency of each of the comments differs significantly at each museum.

While the data from each museum cannot be used to indicate a single type of learning, several trends were museum specific. At the Boston Children's Museum the most frequent comments were reinforcement/coaching verbal observations with forty-two percent of the total comments identified as reinforcement/coaching verbal observations. Ninetyeight reinforcement/coaching verbal observations were calculated for the adults and eighteen reinforcement/coaching verbal observations were calculated for the children. Overall, adults at the BCM verbalized 2.3 times as many comments as the children (See Figure 1).

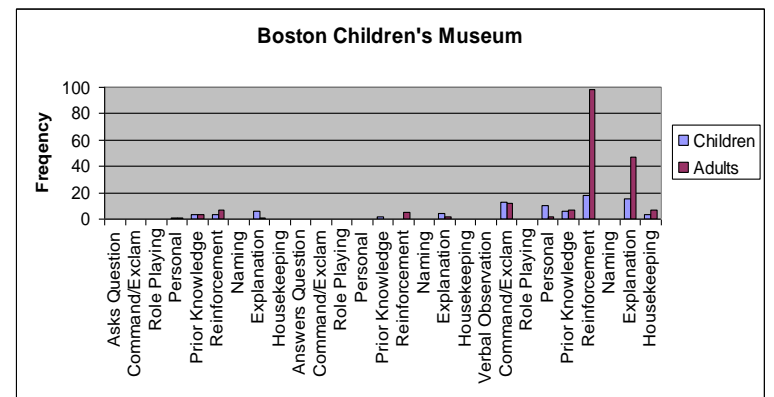

Figure 1. Dialogic Inquiry of Family Conversations in Museum Exhibits Designed for Family Engagement 
At the New England Aquarium the most frequent type of comment was command/exclamation verbal observation. Thirty-eight percent of the total comments were identified as command/exclamation verbal observations. Fifty-three command/ exclamation verbal observations were recorded for the children and thirty-four command/exclamation verbal observations were recorded for the adults (See Figure 2).

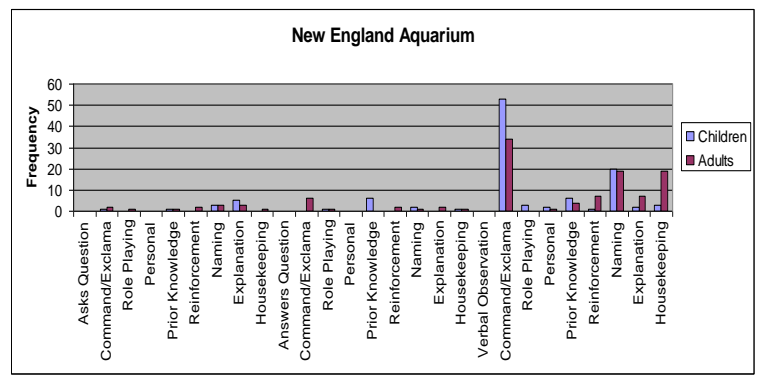

Figure 2. Dialogic Inquiry of Family

Conversations in Museum Exhibits Designed for Family Engagement

The USS Constitution Museum elicited the greatest variety of comments and more questions and role-playing than the other sites. Thirty-six questions were observed at the USS Constitution compared to twenty-five at the BCM and twenty-three at the NEA. Thirteen role-playing comments were recorded at the USS Constitution compared to six at the NEA and zero at the BCM (See Figure 3).

\section{Discussion}

The conversations recorded at each museum are valuable resources for determining what kinds of family learning are taking place in particular exhibits. Each of the coding categories represents a type of dialogue that enables specific kinds of learning, depending on the context.

The USS Constitution Museum exhibit had the longest visitor interaction times, with an average visit time of eight minutes, but ranging from one minute to twenty-four minutes. This exhibit elicited the widest variety of dialogue types, spanning all categories except housekeeping. It also elicited significantly more questions than the other sites.

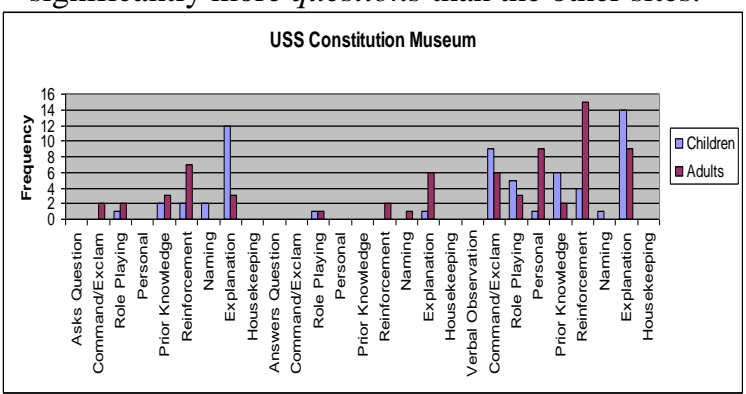

Figure 3. Dialogic Inquiry of Family

Conversations in Museum Exhibits Designed for Family Engagement
Conversations in the categories of reinforcement and explanation were the most prevalent. Also, the frequent incidence of role-playing dialogue was unique to this site and fostered exceptional learning experiences. Through interactive play, children often demonstrated full engagement, risk-taking to reach beyond their comfortable limits, and increased curiosity. Role-playing was essential to their ability to stretch and grow in this imaginatively designed setting.

The comments and corresponding learning that were demonstrated in response to the "All Hands on Deck" exhibit may be linked to some aspects of exhibit design. For instance, the wide variety of dialogical types could be attributed to the diversity of displays within the exhibit. Not only were different aspects of the same topic explored, they were presented in a variety of ways. For instance, although the exhibit was not much larger than those studied at the other two museums, the small space was packed with displays and activities that invited participants to explore information on life as a sailor. For instance, one display recreating a sailor sleeping area and provided text-based interpretation of the setting. Other displays invited visitors to follow written instructions and try their luck at unfurling a sail, scrubbing the deck, or dressing the part of a sailor. In addition, the prevalence of questions, reinforcement and explanation may be related to the generative challenges posed by the exhibit. There were multiple displays that attempted to engage visitors in ways that sometimes seemed unfamiliar to them. In particular, this exhibit provided a number of handson learning experiences that were just outside of their individual knowledge or skill level. As each family approached these displays, they were challenged to gather clues about to how to act at the exhibit and what they were supposed to learn. In many cases, the questions asked related to the intricacies of interpreting the exhibits. The following dialogue shows how family members took on leadership roles to guide other family members through the process. These interactions often took the form of reinforcement and explanation. In the first example the children are constructing knowledge together but an adult is mediating their interaction and providing guidance:

Boy \#1: (Jumps on footrope. Grabs sail. Boy \#2 jumps on.) You have to balance yourself and stuff this in and then after you have to grab this.

You have to attach it! (Holding the sail in his hands.)

Boy \#2: No. You're not supposed to attach it.

Dad: (Jumps on footrope) Yes. Yes. Attach it. Like this. (Demonstrates.)

Dad: But you have to keep yourself upright. Look!

Girl: I need help over here, whoa!

Boy \#2: Papa! 
Dad: Attach this. Then lower it, yes, yes, like that, and then you grab the other rope. (Boy \#1, Boy \#2 and Dad are unfurling the sail.)

Boy \#1: Papa! I did the first square knot. Yes! It works.

Dad: It's moving. It's moving! It's starting to spin!

Boy \#1: You have to balance yourself on the rope!

Boy \#2: Like this?

In this example, the children are fully entering the learning experience with the enthusiastic encouragement of their father. Afterwards, the children from this family were also sharing information without their parents, as is shown in this dialogue:

Girl: (At knot tying station. To herself.) Okay what do we do?

Girl: (Reading sign.) Gotta do a knot. But how do I make it?

Girl: (To Boy \#2) Come here. Come and see this thing.

Girl: Look here. (She demonstrates the knot tying.)

It is interesting to note when children choose to reach out to adults for help, when they experiment or use the signage for guidance, and when they choose to involve or teach each other. They often combine these supports to navigate the exhibit and boost their learning, alternating between independent and collective approaches. Although the range of dialogue was particularly varied at this site, reinforcement and explanation were represented most frequently. In the context of the "All Hands on Deck" exhibit, both of these types of dialogue enabled the development of problem-solving skills as families negotiated their interactions with the exhibits. For instance, in one case, a father was trying to facilitate his children's understanding of the experiential aspect of the exhibit by encouraging them to try things with comments such as, "Do you guys want to try the beds?" After other prompts such as this, the child began to test the limits of the space on his own. For instance, he pointed to the dress-up box and said: "can we play with these?" to which his father replied: "Yeah, Do you want to take your jackets off and try stuff on?" In this situation, the family is learning to problem-solve and to negotiate their involvement with the exhibit through reinforcement and coaching.

As previously mentioned, this exhibit at the USS Constitution was unique in its ability to encourage role-play. In addition to the increased engagement and learning we have been describing, role-play also fostered the development of multiple-perspective taking skills. Visitors engaged in dialogue that demonstrated that they were envisioning what life would have been like in another time and place. This learning was also demonstrated when the visitors enacted roles from the period in history they were learning about. Family members often encouraged these comments in one another. For instance, when a parent asks his or her son, "What kind of sailor are you going to be?" he begins to imagine that he is a sailor, and then exclaims, "Look. I had to eat a rat. They ate rats too." This observation links his imagined world with the current context in which he reflects what he is learning.

This exhibit encourages the development of new knowledge and skills, the development of both individual and collective learning strategies. Specifically, visitors come away with greater historical awareness and perspective taking skills. Whether through role-playing, explanation or reinforced exploration, visitors gained new understandings of life as a sailor.

At the Boston Children's Museum's exhibit "Power Launch", the average engagement time for visitors was two minutes and fifty-two seconds, with some visitors staying just over six minutes. The length of time each group stayed in the exhibit seemed to be heavily influenced by whether it was perceived that other children were waiting to use the exhibit. However, even at times when there was nobody else waiting, a child by themselves was less likely to engage for long compared to someone exploring with their siblings. Furthermore, parents encouraging sustained inquiry and offering explanations guided longer interactions compared to parents who simply provided positive reinforcement.

Reinforcement was the most prevalent type of dialogue, followed closely by explanation. Parents spoke far more frequently than children and few questions were asked. Looking at the data, and the context from which it was drawn, three specific areas of learning emerge. These types of learning are: self-knowledge and confidence, social interaction, and learning content through observation and conversation. The nature of the exhibit had a significant impact on the types of learning that took place. Specifically, the "Power Launch" involved the physical challenge of hoisting a heavy ball with a rope and letting it plunge to force another ball into the air. A series of colored rings suspended above the launch allowed children to observe and remember how high the ball went. In contrast with some of the neighboring exhibits, parents appeared much more involved in the task that their children were attempting. This could be because the fun, physical and results-oriented components of this display intrigued adults and children alike. Also, succeeding at the challenges put forward by the display sometimes required parental involvement, especially for young children.

The power launch exhibit helped children to learn about their capabilities and strengths. For instance, many children made comments about how 
challenging the task of lifting the ball was, making such comments as, "It's heavy." They also frequently announced and celebrated their successes with such comments as, "It went high, hit the clouds." In response, many parents and siblings acknowledged their child/children's accomplishment with praise such as, "Good job" and "that was awesome." These children were learning the extent of their physical abilities and taking pride in the results that they could produce. This kind of positive reinforcement was sometimes complimented by a new understanding by parents and/or children about how much they could handle on their own. For instance, after trying it once together, a mother said to her son, "You want me to let go and do it yourself?" In other situations the children asserted their desire for independence by saying. "I want to do it by myself." This development of selfawareness spanned a variety of coding categories, but was most supported by reinforcement and making connections to prior knowledge and experience.

This exhibit also fostered the development of social interaction skills, encouraged by parents. Parents often reminded their children to share and take turns within and between families. Children sometimes needed to be reminded to allow their siblings a chance with such comments as, "Come over here. Let the baby do it." They were also reminded to share the space with other families with comments such as, "Okay, one more time. Let other people go." In one case, children were encouraged to pull on the rope as a team so that they could be more effective: "Keep going that's it. You can do it together." This social learning generally came out of dialogue coded as reinforcement and coaching. This set of data, illustrating pro-social learning, is an interesting development because museum exhibits are generally designed more for content-specific learning.

In addition, this exhibit allowed for learning through observation and conversation. Children learned such things as spatial awareness, scientific principles, self-/other- awareness, and how to interact with technology. For example, after observing and interacting with the power launch, a child realized, "The air shoots through there!" In another situation, sustained engagement with the display led to a deeper understanding of how the child's actions were affecting the reaction of the machine:

Mom: (With girl on stairs. Pointing to visitor pulling the rope.) See how she pulls it. Watch the ball. Whoa. See, see. See how she pulls it. (Girl runs down the stairs to the exhibit.)

Girl: Watch me. (Girl pulls the rope down.)

Mom: Holy cow.

Girl: Mama.
Mom: Try it again. (Girl pulls the rope at an angle. Lets go.)

Mom: Not as far as the first time.

Girl: Let me try again. (Grabs rope.)

Mom: I think you have to pull it down. You have to pull it lower.

Mom: (Pulls rope straight down. Releases rope.) Which one went higher?

Girl: This one.

With the coaching of the mother, the girl explored how the angle at which the rope was pulled influenced how high the ball could be launched. Through experiencing, interacting with, and discussing the machine, visitors began to uncover some clues as to how it worked. In addition, the importance of being seen and encouraged in the task was central to the experience for a lot of children. The one-on-one attention they are able to get in this setting is likely much more intensive that what they would get in a classroom setting or school visit to a museum. The effect of having an audience, collaborator or guide meant that children were interested in making their learning visible by describing their thought-process and/or asking adults to watch or notice specific things they were trying. This provided an experience in demonstrating knowledge, and showing awareness and intentionality in their own learning process.

Most visits to the jellyfish exhibits at the New England Aquarium were relatively short. On average visitors stayed fifty-two seconds with a standard deviation of thirty-six seconds. This was likely due to the nature of the exhibit space, which was designed to promote continual movement and flow of visitors through the rest of the exhibit.

Perhaps the design of the Amazing Jellies exhibit, in particular the Japanese Sea Nettles and the Moon Jellies which were monitored for this study, also explained the high incidence of command/exclamation and naming comments in the space. Text panels were minimal, including only the name of the jelly species and basic information about its habitat and diet. Therefore, comments mainly described the beauty of, and fascination with, the jellies and their actions, rather than external explanation. On occasion, though, adults and children did draw from family experience and personal knowledge to increase content knowledgebased learning. Based on the families' dialogue and observations, the most common types of learning that took place at the New England Aquarium's Amazing Jellies exhibit included visual observation ("look at this", "oh, look - tiny", "wow, they're beautiful,") and shared excitement (simultaneous "ooooh"), naming ("that's a jellyfish", "moon jellies!"), and sharing of family knowledge and experiences.

Of particular interest were conversations between family members that revealed new information about 
each other's interests and knowledge. For example, in the excerpt below from a conversation between a dad and his ten year-old son, the father learns that his son has an extensive knowledge base about jellies and is markedly impressed with his son's comments:

Boy: These are lots of jellyfish!

Boy: Are these box jellyfish?

Dad: Box jellyfish?

Boy: Box jellyfish. Don't get stung by a box jellyfish.

Dad (reads label): These are Japanese Sea Nettles.

(Dad and Boy move to next tank)

Dad (reading label): The moon jellies.

Boy: They look like moons, don't they?

Dad: They do, don't they?

Boy: (indiscernible)

Dad (with marked excitement and greatly impressed): They do?? How do you know that??

Boy: Animal Planet. They look like UFOs.

Dad (obviously still surprised and impressed):

Animal Planet, really?

In this case, the father learned about his son's interests and knowledge base. By learning from each other, the father and son were able to connect with each other and enhance their interaction with the aquarium's exhibit.

In general, dialogue in this exhibit tended not to be extremely interactive. Often parents and children would speak, but did not necessarily engage in sustained conversation with each other. The following exchange, for example, captures the dialogue between a mother, father and two boys. The father and younger son do not speak at all. The mother and older son speak, but not directly with each other.

Mom: Wow!

Boy: (swims like a jelly)

Mom: They are smaller than the other ones.

Boy: You can't touch it.

Perhaps the reason that parents and children do not always respond to each other's comments is that they are immersed in their own thoughts. What learning potential is gained or lost in an exhibit that elicits more passive, personal and reflective responses? What realizations and connections might still be reached on an individual level, and how much is shared non-verbally that contributes to the families shared understanding? For some, museum visits are an individualized experience that is productive specifically because of the time provided for quiet contemplation. It would be interesting to further explore these types of quiet shared learning experiences that are less reliant on dialogue, problem solving or action and focus more on witnessing something together. While these individual experiences are still important learning events, the independence of family members in this exhibit may be preventing questions from asked and answered, and useful information from being exchanged. While dialogue can help to scaffold learning, those conversations do not need to happen immediately. There may be sustained conversations about this experience subsequent to the museum visit. It is important not to discount the power of awareness, wonder and curiosity in propelling future conversations and learning endeavors.

\section{Conclusion}

It is important to note here that the final dataset contained a number of different variables and indices of learning. For the purposes of this paper, we chose to focus on the differences between adult and child dialogue, and the learning categories they were covering with that dialogue. We could have chosen to focus on and analyze a number of other variables. For instance, we had the information to compare data from families of different composition including number and age of siblings, parents, and grandparents. We also had the information to examine interactions between and among genders. In addition, we touched on but did not go into detail about whether comments fell into the coding categories of asks questions, answers question, or verbal observation. This differentiation was mostly useful for determining if the exhibit was eliciting questions, but could also be looked at in terms of conversation patterns that leave questions unanswered or how closely dialogue is linked to statements/questions of other participants. All of these variables could be analyzed in greater depth with a larger sample size in future studies.

Future research would benefit from more direct interaction with museum visitors so that their perspectives could be taken into account rather than inferred. Interviews or surveys of participants could be used to obtain more detailed and accurate information about their ages, family composition, prior knowledge, exit knowledge, and how they felt about their museum learning experience. By asking for their insights, stronger connections could be made between observed dialogue and visitor perceptions of what types of learning the dialogue represents. Further, digital recorders could be used to track families throughout their experience within a museum. This tracking would allow researchers to capture the range of comments produced by family members across exhibits and follow families when they re-enter certain exhibits. This information would enable researchers to account for differences between families such as their levels of interaction and learning agendas. Tracking families throughout their museum experience could also differentiate between behavior and language patterns that persist throughout the museum experience, and those that are exhibit specific. 
The findings of this study support those of Borun et al. [4], Ash [1], and Ellenbogen, Luke, \& Dierking [5] in that conversation does seem to have an important influence on family learning in museums. These findings have significant implications for museums that wish to engage families in learning experiences. Our research has shown that exhibit design and layout can have a considerable influence on the types of comments elicited by family groups. We have also shown that different types of comments can enable multiple kinds of learning within an exhibit space where language is used as a tool to enhance and promote learning.

Museums wishing to engage families should consider the ways in which their exhibits can elicit dialogue. For example, museums that want to create an environment that triggers sustained involvement with one or two particular topics over the course of the visitors' time in the exhibit space, may wish to create exhibits like the Amazing Jellies exhibit, at the New England Aquarium. In this exhibit, visitors are exposed to stimuli that encourage ongoing reflection about one particular topic - jellyfish. These visitors spend much time naming the jellies and commenting on their movement and appearance. Other museums may wish to elicit a greater range of comments within one exhibit. The "All Hands On Deck" exhibit at the USS Constitution Museum encourages families to move around, jumping between different prompts that elicit a range of responses. While they may not have memorized the details of a single topic, visitors are likely to leave this exhibit with a general understanding of sailor life, and with their curiosity and imaginations activated. Museums seeking to encourage knowledge gathering in combination with team building and self-awareness could learn from the design of the "Power Launch" exhibit at the Boston Children's Museum. This exhibit encourages families to work together and coach each other towards achieving the goal of shooting the ball higher, which can push them to observe scientific principles together and provide positive reinforcement.

It is clear that the design of the exhibit affects not only the way families learn content-specific knowledge, but also the way they springboard into other learning categories from those initial prompts. In addition to seeking knowledge, families are using the exhibit to facilitate a range of social, emotional, imaginative and life-skill based learning. In addition, adults are often taking the opportunity to show their children how to learn by encouraging them to read instructions, experiment, observe, investigate, draw on past knowledge, and ask questions. When designing exhibits, museums should consider the potential for this type of dynamic and far-reaching family knowledge construction.

\section{References}

[1] Ash, D. "Dialogic inquiry in life science conversations of family groups in a museum", Journal of Research in Science Teaching, Wiley Periodicals, 2003, pp.138-162.

[2] Borun, M., Chambers, M., and Cleghorn, A. "Families Are Learning in Science Museums." Curator: The Museum Journal, California Academy of Sciences, 1996, pp.123138.

[3] Borun, M., and Dritsas, J. "Developing FamilyFriendly Exhibits." Curator: The Museum Journal, California Academy of Sciences, 1997, pp.178 - 196.

[4] Borun, M., Chambers, M.B., Dritsas, J., \& Johnson, J.I. ( "Enhancing family learning through exhibits." Curator: The Museum Journal, California Academy of Sciences 1997, pp. 279-295.

[5] Ellenbogen, K.M., Luke, J.J., \& Dierking, D. "Family learning research in museums: An emerging interdisciplinary matrix?" Science Education, Wiley Periodicals, Inc., 2004, pp. 48-58.

[6] Hooper-Greenhill, E. (Ed.), The educational role of the museum, Routledge, London, 1994.

[7] Sandifer, C. (1997, May 15). "Time-based behaviors at an interactive science museum: exploring the differences between weekday/weekend and family/nonfamily visitors." Science Education, 1997, John Wiley \& Sons, Inc. pp. $689-701$. 